DOI: $\underline{10.20472 / E S .2016 .5 .1 .001 ~}$

\title{
IMPACT OF THE GLOBAL FINANCIAL CRISES ON THE MAJOR ASIAN COUNTRIES AND USA STOCK MARKETS AND INTER-LINKAGES AMONG THEM
}

\author{
CENK GOKCE ADAS, BIBIGUL TUSSUPOVA
}

\begin{abstract}
:
This study examines the impact of the global financial crisis on the stock markets returns of China, Japan, India, and USA through E-GARCH model. In addition, it investigates the nature of volatility spillovers between stock indices during the global financial meltdown employing Granger Causality test. Daily stock prices are used for the period from 6th of January, 2006 to 22nd of April 2011. The main findings are as follows. First, in all stock markets high volatility and setback on the daily returns exist due to the financial crisis. Further the global financial crisis less affected Shanghai stock exchange than the other stock markets whereas it influenced the USA stock markets in large extent. Also stock returns volatility get moderated in the major Asian Countries stock markets after post crisis period but it has been remained in the USA stock exchanges. Secondly, Granger causality test shows that after the onset of the financial crisis, the USA stock markets have bidirectional influences on the each of other market, but didn't receive any volatility spillover from major Asian Countries stock markets. Indian stock market experiences volatility spillover from all the stock markets. Japanese stock market receives volatility spillover only from USA stock markets. However, Shanghai stock exchange doesn't experience any volatility spillover from the other stock markets.
\end{abstract}

\section{Keywords:}

Volatility Spillover; Financial crisis; China, Japan, India and USA Stock Markets; E-GARCH; Granger Causality.

JEL Classification: C58, F65, G01

\section{Authors:}

CENK GOKCE ADAS, Istanbul University, Faculty of Economics, Turkey, Email: BIBIGUL TUSSUPOVA, Ministry of National Economy,, Kazakhstan, Email:

\section{Citation:}

CENK GOKCE ADAS, BIBIGUL TUSSUPOVA (2016). IMPACT OF THE GLOBAL FINANCIAL CRISES ON THE MAJOR ASIAN COUNTRIES AND USA STOCK MARKETS AND INTER-LINKAGES AMONG THEM. International Journal of Economic Sciences, Vol. V(1), pp. 1-17., 10.20472/ES.2016.5.1.001 


\section{Introduction}

Some significant improvement and growth have begun in the last thirty years' world economy by force of the globalization which can economically be defined as the free movement of goods, and capital in-between countries. The liberalization of commerce and the removing of the rules which obstruct the movement of the capital by the countries one after another started an integration process among the national economies. The positive sides of this integration aside, the spreading of a problem from one economy to another has become a frequently encountered fact. While expecting the international financial integration to reduce the macroeconomic volatility, the liberalization of the capital account may bring the countries to an unprotected position against the crisis (Adas, and Kartalli, 2014).

As it is mentioned in Ke, Wang, and Murray, (2010)'s article, "the volatility of a financial market might be affected by the volatilities of other markets, besides the influence that arises from its strong serial autocorrelations. This kind of cross-market volatility transmission is known as volatility spillover." On the hand, Forbes, and Rigobon, (1999) explain "the contagion as a significant increase in the cross-market correlation during the period of economic disturbances. If two markets are reasonably correlated during the periods of stability, then a negative shock to one of the markets has ripple effects and creates a significant increase in market co-movement. This would be regarded as the contagion or spillover effect of the two markets".

Due to the global financial crisis, major Asian countries and USA stock markets were affected by different degrees. In this study it has been adapted three major Asian and two USA daily stock indices for periods from 6 January 2006 to 22 April 2011 namely Shanghai composite stock index (SSE) from China, Nikkei 225 stock index (Nikkei225) from Tokyo, Bombay sensitive 30 index (BSE30) from India, Standard and Poor's 500 index (S\&P500) from USA, and New York stock exchange index (NYSE) from USA.

The aim of the paper is to investigate the impact of the global financial crisis on stock returns using E-GARCH model (Exponential Generalized Autoregressive Conditional Heteroskedasticity) and find out which stock markets were more or less affected. Also this paper examines inter linkages among stock indices during the global financial meltdown using Granger Causality test and shows cross-market volatility transmission -the volatility of a financial market might be affected by the volatilities of other markets. In addition to that, the study investigates whether the stock prices in Asia are cointegrated with the world markets, namely the US.

This paper is organized as follows: Section two considers literature review, Section three presents the methodology and data used in the study, Section four present the empirical results and finally, Section five discusses the results of the empirical studies. 


\section{Brief Literature Review}

The asymmetric volatility, temporary volatility, and permanent volatility of stock markets returns is being important in recent years. A lot of researchers have been studied the models to estimate the impact of the global financial crisis on stock returns of different stock markets.

Ke, Wang, Muray, (2010) "estimated volatility spillover effect between Shanghai and primary stock markets abroad, particularly New York, London, and Frankfurt, and also between Shanghai stock market and the emerging countries stock market (Hong Kong and Korea) through GARCH and E-GARCH models. Their results revealed that after onset the financial crisis the stock markets in developed countries have bidirectional influences on each other. Before the financial crisis came from the US market, the Shanghai B-share market was only influenced by the Japan market. Furthermore, after the crisis, the Shanghai B-share market does not receive any significant volatility transmission from other markets."

Lim, Brooks, Kim, (2008) studied the efficiency of the eight Asian stock markets in order to find the effect of Asian financial crisis 1997, Hong Kong stock market was the major sacrifice of the crisis.

Olowe (2009) examined the relation between stock returns and volatility in Nigeria using E-GARCH-in mean model in the view of banking and insurance reform, stock market crash and the global financial crisis. Using daily returns over the period 4 January 2004 to January 9, 2009, he estimated high volatility persistence, asymmetric properties and risk-return relationship for the Nigerian stock market.

Rafaqet, and Afzal, (2012) used E-GARCH model to estimate the effect of the global financial meltdown on Pakistani and Indian stock markets and found that negative shocks have more pronounced impact on the volatility than positive shocks. These stock markets also faced persistent volatility clustering. They concluded that recent global financial crisis made negative impact on stock returns and this impact is stronger on Indian stock market than on Pakistani stock market.

Verma, and Mahajan (2012) applied an augmented E-GARCH model to figure the demeanor of Indian stock prices for the global financial crisis. The study implied that the impact of U.S. financial dissolving on the stock return volatility of Indian stock market has been significant.

Abidin (2012) investigated the asymmetric volatility in New Zealand stock exchange for the time period 2007-2008 by employing two models, E-GARCH and T-GARCH, to capture the asymmetric effects on New Zealand stock exchanges The results provided 
evidences of the presence of asymmetric volatility in the New Zealand stock market for the entire time period of study.

Singh (2010) studied the relationship between Chinese and Indian market with developed markets. Using daily data for the time period between 2000 to 2009, stock market indices for China, India, Japan, Hong Kong, United States, and United Kingdom were estimated. He used the correlation and Granger Causality test and Error Correction model. It was found that Chinese and Indian markets are both correlated with all four major markets during the estimation period.

The connections among the ASEAN-3+5 countries (China, Japan, Korea, Malaysia, Singapore, the Philippines, Thailand, Indonesia) and US stock exchanges for the time period of 1997 Asian financial crisis analysed by Royfaizal, Lee, Azali, (2009) using Granger Causality test. It was found that ASEAN-3+5 and US stock markets are related each other for the global financial crisis and post-crisis periods.

Sakthivel, Bodkhe, and Kamaiah, (2012) investigated the statistical relationship and volatility channel over stock markets by applying Bivariate $\mathrm{GARCH}$ model for main stock exchanges (India, Japan, USA and Australia). They found long run cointegrated relationship over stock indices in the applied Johansen method Moreover, incoming external shock was experienced by Japan and US stock exchanges at the same time and then conducted to other Asian and European stock markets. Bivariate GARCH model showed that there is a bidirectional volatility spillover between US and Indian stock markets. Because these two economies were powerfully united through international trade and investment.

Sakthivel, and Kamaiah, (2012) tried to examine the interdependence between the US, Asian and European stock exchanges. They used daily stock prices covering the period of time between 1998 and 2010. Short and long run relationships were estimated via Johansen cointegration method. Their results displayed significant cointegrated vector over the stock prices indices. Lastly, the effect of the US financial market on the Indian stock exchanges was much higher than opposite way.

\section{Methodology and Data}

\subsection{E-GARCH Model Specification}

As it is mentioned by (Engle, 2001) "The ARCH and GARCH models, which stand for autoregressive conditional heteroskedasticity and generalized autoregressive conditional heteroskedasticity, are designed to deal with just this set of issues. They have become widespread tools for dealing with time series heteroskedastic models. The goal of such models is to provide a volatility measure-like a standard deviationthat can be used in financial decisions concerning risk analysis, portfolio selection and derivative pricing." 
Common GARCH model contains a coefficient that can catch statistical relationship between stock returns and conditional variance. These models are called asymmetric or leverage volatility models. "The asymmetric response of volatility to positive or negative shocks is well known in the finance literature as the asymmetric/leverage effect of the stock market returns." (Karanasos, Kim, sited to Black 1976). "Asymmetric/leverage effects means whether negative shock of bad news is more pronounced than positive shock of good news for stock markets or vice versa" (Rafaget and Afzal, 2012).

One of the earliest asymmetric information GARCH models is the EGARCH model. This model first proposed by Nelson (1991). "The EGARCH model is more general than the standard GARCH model in that it allows innovations of different signs to have a differential effect on volatility than does the standard GARCH model. Also in contrast to the conventional GARCH specification which requires nonnegative coefficients, the EGARCH model by modelling the logarithm of the conditional variance does not impose the no negativity constrains on the parameter space" (Karanasos, Kim, 2000).

General mean and conditional specification of E-GARCH is as follows Verma and Mahajan (2012)'s model;

Mean Specification for any time series variable $X_{t}$

$$
X_{t}=c+\mu_{t}
$$

Variance Specification

$$
\log \left(\sigma_{t}^{2}\right)=\omega+\alpha \log \left(\sigma_{t-1}^{2}\right)+\gamma\left|\mu_{t-1} / \sigma_{t-1}\right|+\beta\left(\mu_{t-1} / \sigma_{t-1}\right)
$$

In the equation (2), ' $\alpha$ ' is called GARCH term. It evaluates effect of final periods' variance. "A positive ' $\alpha$ ' indicates volatility clustering implying that positive price changes are associated with further positive changes and vice versa. The coefficient ' $Y$ is the ARCH term that measures the impact of news about volatility from the previous period on current period volatility" (Verma and Mahajan, 2012). In other words, ARCH and GARCH term cover the effects of new and old news respectively. $\mathrm{ARCH}$ term points out how volatility is affected by current news. However, GARCH term suggests how volatility is connected by old news. ' $\beta$ ' assesses the "leverage effect and it is supposed to be negative. It means that bad news has a larger effect on volatility than the good news of the same magnitude." (Verma and Mahajan, 2012)

Following the Verma and Mahajan (2012)'s model, the mean and variance specification for stock market index;

Mean specification for stock markets: 
$R_{t}=\delta+\beta X_{t}+\varepsilon_{t}$

In the equation (3), $R_{t}$ is stock return series, $\delta$ denotes for constant, $X_{t}$ is independent variable, and $\beta$ is the coefficient of independent variable. $\boldsymbol{\varepsilon}_{\mathbf{t}}$ is residuals. Finally, subscription 't' symbolize the time.

Conditional specification for stock markets:

$$
\log \left(\sigma_{t}^{2}\right)=\omega+\sum_{i=1}^{p} \alpha\left|\mu_{i} / \sigma_{t-i}\right|+\sum_{j=1}^{m} \gamma_{j} \mu_{t-j} / \sigma_{t-j}+\sum_{k=1}^{q} \beta_{k} \log \left(\sigma_{t-k}^{2}\right)
$$

In conditional variance specification, equation (4), Akaike Information Criterion (AIC) is used for determination of $\mathrm{p}, \mathrm{m}, \mathrm{q}$. The influence of global financial crisis on stock markets are considered by employing dummy variables. Dummy $D_{1}$ is for period of global financial crisis. Dummy $D_{2}$ refers for period of after the financial crisis. The new mean equation including dummy variables as follows:

$R_{t}=\delta+a_{1} D_{1}+\mu_{t}$

In the equation (5), $a_{1}$ captures the differences in mean stock incomes as a result of financial crisis. In other words, it measures the effect of the financial crisis on stock incomes.

We are going to estimate following modified variance equation for the all stock markets. Verma and Mahajan, (2012)

$$
\log \left(\sigma_{t}^{2}\right)=\omega+\sum_{i=1}^{p} \alpha \mu_{t-i} / \sigma_{t-i}+\sum_{j=1}^{m} \gamma_{j} \mu_{t-j 1} / \sigma_{t-j}+\sum_{k=1}^{q} \beta_{k} \log \left(\sigma_{t-k}^{2}\right)+\tau_{3} D_{1}+\tau_{4} D_{2}
$$

In the equation (6), $\tau_{3}$ describes the sudden change of direction in Return-Volatility for the time period of financial crisis and $\tau_{4}$ illustrate post crisis period. To understand the volatility spillover, coefficient of $\omega, \alpha, \gamma$ and $\beta$ are going to be calculated.

\subsection{Granger Causality Test Specification}

"The basic 'Granger Causality' definition is quite simple. Suppose that we have three terms, $\boldsymbol{X}_{t}, \boldsymbol{Y}_{\boldsymbol{t}}$, and $\boldsymbol{W}_{\boldsymbol{t}}$, and that we first attempt to forecast $\boldsymbol{X}_{t+1}$ using past terms of $\boldsymbol{X}_{t}$ and $\boldsymbol{W}_{t}$. We then try to forecast $\boldsymbol{X}_{t+1}$ using past terms of $\boldsymbol{X}_{t}, \boldsymbol{Y}_{t}$, and $\boldsymbol{W}_{t}$. If the second forecast is found to be more successful, according to standard cost functions, then the past of $Y$ appears to contain information helping in forecasting $\boldsymbol{X}_{t+1}$ that is not 
in past $\boldsymbol{X}_{\boldsymbol{t}}$ or $\boldsymbol{W}_{t}$. In particular, $\boldsymbol{W}_{\boldsymbol{t}}$ could be a vector of possible explanatory variables. Thus, $\boldsymbol{Y}_{t}$ would 'Granger cause' $\boldsymbol{X}_{t+1}$ if (a) $\boldsymbol{Y}_{t}$ occurs before $\boldsymbol{X}_{t+1}$; and (b) it contains information useful in forecasting $\boldsymbol{X}_{t+1}$ that is not found in a group of other appropriate variables" (Anil Seth, Scholarpedia.org ).

According to Stern (2011), "the simplest test of Granger causality requires estimating the following two regression equations:

$$
\begin{aligned}
& y_{t}=\beta_{1,0}+\sum_{i=1}^{p} \beta_{1, i} y_{t-i}+\sum_{j=1}^{p} \beta_{1, p+j} x_{t-j}+\varepsilon_{1 t} \\
& x_{t}=\beta_{2,0}+\sum_{i=1}^{p} \beta_{2, i} y_{t-i}+\sum_{j=1}^{p} \beta_{2, p+j} x_{t-j}+\varepsilon_{1 t}
\end{aligned}
$$

Where $p$ is the number of lags that adequately models the dynamic structure. If the $p$ parameters $\beta_{1, p+j}$ are jointly significant then the null that " $X$ " does not Granger cause " $Y$ " can be rejected. Similarly, if the $p$ parameters $\beta_{2, p+j}$ are jointly significant then the null that $Y$ does not Granger cause $X$ can be rejected" (Stern 2011).

\subsection{Data}

In our empirical analysis we use daily indices of SSE composite, BSE-30, Nikkei-225, S\&P 500, and NYSE for the period $6^{\text {th }}$ January 2006 to $22^{\text {nd }}$ April 2011. The data were obtained from Yahoofinance.com. Following Ke, Wang, and Murray, (2010) stock return is calculated as:

$$
R_{t}=\log P_{t}-\log P_{t-1}
$$

Where $R_{t}$ represents stock return at time t

$P_{t}$ represents stock market index at time t

$P_{t-1}$ represents stock market index at time t-1

To investigate the volatility of stock returns, $R_{t}$ has been calculated. The entire period of the study is divided into three parts. Period 1 is pre-crisis period [ $6^{\text {th }}$ of January, 2006 to $21^{\text {th }}$ of January, 2008]. Period 2 is crisis-period [22 $2^{\text {nd }}$ of January, 2008 to $25^{\text {th }}$ of March, 2009]. And period 3 is post-crisis period [26 th of March, 2009 to $22^{\text {nd }}$ of April, 2011]. Hence, the effect of the breakdown on the volatility of the stock markets is studied in the study by including the empirical results for three periods. In the following sections, to understand the effect of the global financial crisis on stock returns volatility, two dummy variables are estimated. 


\subsubsection{Summary Statistics}

Table 1 and Table 2 display the basic statistical information about the stock return series for three sub-periods as well as entire period.

Table 1: Summary statistics of SSE composite stock exchange for whole and sub periods.

\begin{tabular}{|c|c|c|c|c|}
\hline & $\begin{array}{c}\text { Entire Period } \\
\left(6^{\text {th }} \text { of January, }\right. \\
2006 \\
\text { to } 22^{\text {nd }} \text { of April, } \\
2011)\end{array}$ & $\begin{array}{c}\text { Period } 1 \\
\left(6^{\text {th }} \text { of January, }\right. \\
2006 \\
\text { to } 21^{\text {st }} \text { of January, } \\
2008)\end{array}$ & $\begin{array}{c}\text { Period } 2 \\
\left(22^{\text {nd }} \text { of January, }\right. \\
2008 \\
\text { to } 25^{\text {th }} \text { of March, } \\
2009)\end{array}$ & $\begin{array}{c}\text { Period } 3 \\
\text { (26 } 6^{\text {th }} \text { of March, } \\
2009 \\
\text { to } 22^{\text {nd }} \text { of April, } \\
2011)\end{array}$ \\
\hline Mean & 0.000298 & 0.001195 & -0.001123 & 0.000220 \\
\hline Median & 0.000569 & 0.001656 & -0.001029 & 0.000416 \\
\hline Maximum & 0.039235 & 0.022560 & 0.039235 & 0,020320 \\
\hline Minimum & -0.040199 & -0.040199 & -0.034933 & -0.030326 \\
\hline Std.Dev. & 0.008535 & 0.007895 & 0.011978 & 0.006526 \\
\hline Skewness & -0.448397 & -1.023945 & 0.180802 & -0.729033 \\
\hline Kurtosis & 5.649952 & 6.296177 & 3.878891 & 5,287909 \\
\hline $\begin{array}{l}\text { Jargue-Bera } \\
\text { (Probability) }\end{array}$ & $\begin{array}{l}438.9355 \\
(0.000000)\end{array}$ & $\begin{array}{l}321.8784 \\
(0.000000)\end{array}$ & $\begin{array}{l}11.10192 \\
(0.003884)\end{array}$ & $\begin{array}{c}164.9975 \\
(0.000000)\end{array}$ \\
\hline Observations & 1346 & 513 & 295 & 538 \\
\hline
\end{tabular}

Source: Results from Eviews-7

Positive signs for excess kurtosis mean that the stock market returns series exhibit leptokurtic distribution. Standard deviation estimates volatility of stock returns. In both cases there are high standard deviations of stock returns during the crisis period, it means that high volatility exists due to financial crisis in Shanghai composite stock exchange as well as in India stock exchange.

Table 2: Summary statistics of BSE-30 stock exchange for whole and sub periods.

\begin{tabular}{|c|c|c|c|c|}
\hline & $\begin{array}{c}\text { Entire Period } \\
\left(6^{\text {th }} \text { of January, }\right. \\
2006 \\
\text { to } 22^{\text {nd }} \text { of April, } \\
2011)\end{array}$ & $\begin{array}{c}\text { Period 1 } \\
\text { (6 } 6^{\text {th }} \text { of January, } \\
2006 \\
\text { to } 21^{\text {st }} \text { of } \\
\text { January, 2008) }\end{array}$ & $\begin{array}{c}\text { Period } 2 \\
\left(22^{\text {nd }} \text { of January, }\right. \\
2008 \\
\text { to } 25^{\text {th }} \text { of March, } \\
2009)\end{array}$ & $\begin{array}{c}\text { Period } 3 \\
\text { (26 } 6^{\text {th }} \text { of March, } \\
2009 \\
\text { to } 22^{\text {nd }} \text { of April, } \\
2011)\end{array}$ \\
\hline Mean & 0.000237 & 0.000519 & -0.000917 & 0.000511 \\
\hline Median & 0.000543 & 0.000848 & -0.000974 & 0.000564 \\
\hline Maximum & 0.069444 & 0.028954 & 0.034312 & 0.069444 \\
\hline Minimum & -0.050397 & -0.033422 & -0.050397 & -0.026094 \\
\hline Std.Dev. & 0.008363 & 0.007086 & 0.012233 & 0.006686 \\
\hline Skewness & 0.111931 & -0.503933 & -0.084915 & 2.091368 \\
\hline Kurtosis & 8.958181 & 5.711592 & 3.695189 & 24.94130 \\
\hline $\begin{array}{l}\text { Jargue-Bera } \\
\text { (Probability) }\end{array}$ & $\begin{array}{l}1931.552 \\
(0.000000)\end{array}$ & $\begin{array}{l}176.4364 \\
(0.000000)\end{array}$ & $\begin{array}{l}6.060205 \\
(0.048311)\end{array}$ & $\begin{array}{l}10685.11 \\
(0.000000)\end{array}$ \\
\hline Observations & 1304 & 506 & 284 & 514 \\
\hline
\end{tabular}

Source: Results from Eviews-7 
"The daily mean returns for the sub-periods as well as the entire period are approximately zero. It means that large number of rational profit maximizers should be equally distributed among stock buyers and sellers. Mean returns are comparatively more before the crisis period than during the crisis, even higher in the post crisis period" (Satish Verma, 2012 sited to Tsay, 2005). Hence giving information that financial breakdown has made an obstacle on the daily stock returns of the Shanghai and Indian stock indices.

Negatively skewed return series before and post crisis period in case of Shanghai composite stock exchange also negatively skewed return series before and during the crisis period in case of Indian stock exchange describes that irregularly low stock return days happened more often than irregularly high stock return days. From this assumption we can conclude that during the crisis period in Shanghai composite stock exchange high return days happened more often than low stock return days however in Indian stock exchange the situation occurred in opposite case i.e. during the crisis period in Shanghai composite stock exchange high return days occurred more frequently than in Indian stock exchange.

The other stock markets such Nikkei-225, S\&P 500, and NYSE show similar behaviors like SSE composite and BSE-30. Also the existence of high standard deviations of stock returns during the crisis period, means that high volatility is remained due to the financial crisis in all stock markets.

\subsubsection{Unit Root Test}

Taking the difference of the time series to make them stationary, we gain the statistical adequacy, which is achieved at the expense of losing valuable long-run information. To provide further estimations time series have to be stationary. Otherwise, "spurious regression" might appear. It is accepted to use Augmented Dickey-Fuller test to check if time series is stationary or non-stationary. The test results for SSE composite, BSE30, and Nikkei-225 are given in Table 3, moreover for S\&P 500 and NYSE are described in Table 4.

Table 3: Unit root test for SSE composite, BSE-30 and Nikkei-225.

\begin{tabular}{|l|l|l|l|}
\hline Stock return & \multicolumn{1}{|c|}{ SSE composite } & \multicolumn{1}{c|}{ BSE-30 } & \multicolumn{1}{c|}{ Nikkei-225 } \\
\hline ADF statistic & $-36.69063(0.0000)$ & $-33.58152(0.0000)$ & $-37.65205(0.0000)$ \\
\hline ADF $(\mathbf{I})$ & $-36.72070(0.0000)$ & $-33.59569(0.0000)$ & $-37.65730(0.0000)$ \\
\hline ADF $(I \& T)$ & $-36.78340(0.0000)$ & $-33.58374(0.0000)$ & $-37.64319(0.0000)$ \\
\hline
\end{tabular}

Source: Results from Eviews-7

Note: ADF test without constant and trend terms, ADF $(I)$ test permits only constant term, ADF (I\&T) allows constant and trend terms. P-values of the ADF test are given in the Brackets. 
Table 4: Unit root test for S\&P 500 and NYSE.

\begin{tabular}{|l|l|c|}
\hline \multicolumn{1}{|c|}{ Stock return } & S\&P 500 & NYSE \\
\hline ADF statistic & $-30.79140(0.0000)$ & $-31.07221(0.0000)$ \\
\hline ADF $($ I) & $-31.07221(0.0000)$ & $-31.06093(0.0000)$ \\
\hline ADF $($ I\&T) & $-30.78037(0.0000)$ & $-31.05639(0.0000)$ \\
\hline
\end{tabular}

Source: Results from Eviews-7

Note: ADF test without constant and trend terms, $\operatorname{ADF}(\mathrm{I})$ test permits only constant term, ADF(I\&T) allows constant and trend terms. Pvalues of the ADF test are given in the Brackets.

In the Table 3 and Table 4 display test result of ADF, ADF(I), and ADF(I\&T). These test results prove that each of the time series does not have a unit root. Hence, all stock return series are stationary processes.

\section{Empirical Results}

\subsection{Estimation of E-GARCH Model}

Estimation of E-GARCH models for SSE composite, BSE-30, Nikkei-225, S\&P 500, and NYSE are given in the Tables 5. Dummy variables for financial crisis and post crisis are incorporated in the E-GARCH models to see impact of financial crisis on stock returns.

Table 5: Parameter Estimates of E-GARCH model for Shanghai composite stock exchange and Indian stock exchange.

\begin{tabular}{|c|c|c|c|}
\hline \multirow{2}{*}{ Variables } & \multicolumn{3}{|c|}{ Coefficients (Probabilty) } \\
\hline & SSE composite & BSE-30 & Nikkei-225 \\
\hline \multicolumn{4}{|l|}{ Mean Equation } \\
\hline$\delta$ & $0.000660(0.0006)$ & $0.000506(0.0014)$ & $-0.000134(0.0418)$ \\
\hline$a_{1}$ & $-0.001680(0.0086)$ & $-0.001675(0.0062)$ & $-0.000956(0.0053)$ \\
\hline \multicolumn{4}{|l|}{ Variance Equation } \\
\hline$\omega$ & $-0.416477(0.0000)$ & $-0.644639(0.0000)$ & $-0.663649(0.0000)$ \\
\hline$\alpha(\mathrm{ARCH}$ effect) & $0.136407(0.0000)$ & $0.262676(0.0000)$ & $0.139672(0.0000)$ \\
\hline Y (Leverage effect) & $-0.017720(0.0455)$ & $-0.114367(0.0000)$ & $-0.169615(0.0000)$ \\
\hline$\beta$ (GARCH effect) & $0.967107(0.0000)$ & $0.955135(0.0000)$ & $0.947549(0,0000)$ \\
\hline
\end{tabular}




\begin{tabular}{|c|c|c|c|}
\hline$\tau_{3}$ & $0.021457(0.0336)$ & $0.035271(0.0500)$ & $0.065364(0.0011)$ \\
\hline$\tau_{4}$ & $-0.016904(0.0036)$ & $-0.020861(0.0370)$ & $0.020517(0.0376)$ \\
\hline \multicolumn{4}{|c|}{ Diagnostic test } \\
\hline Q-Stat & All insignificant & All insignificant & All insignificant \\
\hline \multicolumn{4}{|l|}{ ARCH-LM } \\
\hline F-Statistics & $0.025268(0.3787)$ & $1,034521(0.3093)$ & $0.376789(0.5394)$ \\
\hline $\mathrm{N}^{*} \mathrm{R} 2$ & $0.025305(0.3736)$ & $1,035289(0.3089)$ & $0.377261(0.5391)$ \\
\hline
\end{tabular}

Source: Results from Eviews-7

Note: Number of Lag determination has been calculated by Akaike Information Criterion (AIC). It has been estimated $5 \%$ significance level.

The first column of Table 5 estimates SSE composite stock exchange. From mean equation we can see the coefficient of the crisis $a_{1}$ of Shanghai composite stock index is significant at $5 \%$ level of. It capture negative sign which reveals that there is low effect of financial crisis on stock return. The reason for that stock returns were decreased by 0.17 percent due to the crisis. The coefficient of $\alpha$ is 0.136 which is significant, by means that characterizing the existence of $\mathrm{ARCH}$ effect which involves that recent news had an impact on the current period. Positive $\beta$ is highly significant and contains 0.967 value which implies the existence of GARCH effect i.e. volatility clustering continues in this stock exchange and market volatility vanishes in a long times. In other words, favourable changes in the past are pursued by more favourable changes and the opposite. Shanghai composite stock exchange confronts asymmetric volatility. Y (i.e. -0.017720 ) has negative coefficient. It provides for the existence of leverage effect. By means that the impact of negative news is more sounded. The estimated parameter of dummy variable for financial crisis period $\tau_{3}$ is significant. It has a favourable effect on market volatility. In other words financial crisis increased only 2.1 percent stock volatility on Shanghai stock exchange. The coefficient of dummy variable for post-crisis period $\tau_{4}$ is significant and has opposite sign. It estimates that market volatility softened when the impact of financial crisis reduced.

The second column of Table 5 estimates BSE-30 stock market. Mean equation implies the coefficient of the crisis $a_{1}$ of Indian stock exchange. It is significant at 5\% level. It captures the negative sign which explains that there is also low effect of financial crisis on stock return. It was diminished by 0.17 percent due to the crisis. The coefficient of $\alpha$ is significant and its value is 0.263 . In that connection, the coefficient of $\alpha$ represents the existence of $A R C H$ effect - recent past news had an impact on the current period stock returns. Value of parameter $\beta$ is 0.955 . It explains the size of volatility clustering. Thus, strength of volatility clustering predominates the Indian stock exchange. If the market volatility is stubborn, then it takes long period of time because of the strength 
of volatility. This is in common it follows favourable changes in the past are pursued by more favourable changes and the opposite. Coefficient of $y$ has significant negative sign. It means that there is effect of asymmetric information in this stock market opposite shock has more strong effect on the stock volatility than the favourable shock. Estimated value of parameter of dummy variable for financial crisis period, $\tau_{3}$, has significant and favourable effect on stock return. Its value of 0.035 approves that the financial crisis raised the stock volatility by $3.5 \%$. The coefficient of dummy variable for post-crisis period, $\tau_{4}$, is significant and its negative sign shows that stock volatility smoothen after March, 2009. If the effect of financial crisis diminishes, result of that market volatility will decrease.

The third column of Table 5 estimates Nikkei-225 stock exchange. Mean equation shows us coefficient of the crisis $a_{1}$ of Nikkei-225 stock exchange has significant negative sign at $5 \%$ level. Its value of -0.001 reveals that there is low effect of financial crisis on stock return. It means that stock return of Nikkei-225 decreased only by 0.10 percent due to the financial crisis. The value of coefficient of $\alpha$ is 0.140 and significant. By means that characterizing the existence of $\mathrm{ARCH}$ effect which involves that recent news had an impact on the current period. The value of coefficient, $\beta$, is 0.948 . This gives the importance of the size of volatility clustering and the existence of volatility clustering predominates the Nikkei-225. Value of coefficient, $\gamma$, has significant negative sign. There exists asymmetric information effect exists on the stock market opposite shock has more powerful effect on the stock volatility than the favourable shock. Estimated parameter of dummy variable for financial crisis period, $\tau_{3}$, has significant and favourable effect on stock return. Its value of 0.065 approves that the financial crisis raised the stock volatility by $6.5 \%$. The coefficient of dummy variable for post-crisis period, $\tau_{4}$, has significant positive sign. It mean that market volatility continued after March, 2009. 
Table 6: Parameter Estimates of E-GARCH model for S\&P 500 and NYSE

\begin{tabular}{|c|c|c|}
\hline \multirow{2}{*}{ Variables } & \multicolumn{2}{|c|}{ Coefficients (Probability) } \\
\hline & S\&P 500 & NYSE \\
\hline \multicolumn{3}{|l|}{ Mean Equation } \\
\hline$\delta$ & $0.000149(0.0093)$ & $0.000137(0,0087)$ \\
\hline$a_{1}$ & $-0.001358(0.0023)$ & $-0.001359(0,0011)$ \\
\hline \multicolumn{3}{|l|}{ Variance Equation } \\
\hline$\omega$ & $-0.425420(0.0000)$ & $-0.433836(0.0000)$ \\
\hline$\alpha(\mathrm{ARCH}$ effect) & $0.084729(0.0000)$ & $0.091953(0.0000)$ \\
\hline Y (Leverage effect) & $-0.172082(0.0000)$ & $-0.182689(0.0000)$ \\
\hline$\beta$ (GARCH effect) & $0.968428(0.0000)$ & $0.968531(0.0000)$ \\
\hline$\tau_{3}$ & $0.070835(0.0000)$ & $0.071797(0.0000)$ \\
\hline$\tau_{4}$ & $0.024495(0.0000)$ & $0.023180(0.0000)$ \\
\hline \multicolumn{3}{|l|}{ Diagnostic test } \\
\hline Q-Stat & All insignificant & All insignificant \\
\hline \multicolumn{3}{|l|}{ ARCH-LM } \\
\hline F-Statistics & $8.529257(0.0036)$ & $8.770448(0.0031)$ \\
\hline $\mathrm{N}^{*} \mathrm{R} 2$ & $8.487652(0.0032)$ & $8.726094(0.0035)$ \\
\hline
\end{tabular}

Source: Results from Eviews-7

Note: Number of Lag determination has been calculated by Akaike Information Criterion (AIC). It has been estimated $5 \%$ significance level.

The first column of Table 6 estimates S\&P 500 stock exchange. From mean equation we can see the coefficient of the crisis $a_{1}$ of Shanghai composite stock exchange is significant at $5 \%$ level. Its negative sign displays the effect of crisis on stock returns. It was decreased by 0.014 percent due to the financial crisis. The coefficient of $\alpha$ is significant and its value is 0.085 . By means that characterizing the existence of $\mathrm{ARCH}$ effect which involves that recent news had an impact on the current period. The coefficient of $\beta$ is positive highly significant and contains 0.968 value which implies the presence of GARCH effect i.e. volatility clustering exists in this stock market and volatility take long times to decay. This illustrates that favourable changes in the past are pursued by more favourable changes and opposite. Shanghai composite stock 
exchange confronts effect of asymmetric information in the volatility of stock return. Its value of coefficient, $\gamma$, is -0.0172082 . It provides for the existence of leverage effect the effect of negative news is more stressed. The coefficient of dummy for crisis period, $\tau_{3}$, is significant and has positive effect on market volatility. It means that recent global financial crisis increased $7.1 \%$ volatility of stock return on S\&P 500 . Positive significant coefficient of $\tau_{4}$ estimates that volatility was still remained after the post crisis period.

The second column of Table 6 estimates behaviour of NYSE stock exchange. Mean equation shows us coefficient of the crisis $a_{1}$ of NYSE stock exchange is significant at $5 \%$ level and has negative sign which unveils that there is low effect of crisis on stock return. It means that stock return of NYSE diminished only by 0.013 percent due to the crisis. The coefficient of $\alpha$ is 0.912 which is significant. By means that characterizing the existence of $\mathrm{ARCH}$ effect which involves that recent news had an impact on the current period. The parameter of $\beta$ displays size of volatility clustering. Its value is 0.968 . That implies that existence of volatility clustering predominates the NYSE. If the market volatility is stubborn, then it takes long period of time because of the strength of volatility. In common it exhibits positive changes in the past are followed by further positive changes and vice-versa. Estimated value of coefficient, $\gamma$, is -0.182 . It is significant. Three exists asymmetric information impact on this stock market and opposite shock has more strong effect on the stock volatility than the favourable shock. Dummy coefficient for crisis period, $\tau_{3}$, is significant and has positive impact on stock return. This information approves that recent financial crisis raised stock volatility by $7.2 \%$. Finally, estimated value of dummy coefficient $\tau_{4}$ is significant and has positive sign. It mean that market volatility continued after March, 2009.

Moreover, Q-Stat values up to 36 lags are insignificant. It means that our model is free from autocorrelation. Also the insignificant ARCH-LM test statistic in both stock markets unveils that standardized residuals did not exhibit additional ARCH effect, thereby denoting that variance equations are well specified. 


\subsection{Empirical Results of Granger Causality Test}

Table 7: Estimated Results of Granger Causality test

\begin{tabular}{lccc} 
& Obs & F-Statistic & Prob. \\
\hline \hline NIKKEI_225 BSE_30 & 293 & 10.7278 & $3 . E-05$ \\
BSE_30 does not Granger Cause NIKKEI_225 & & 0.32055 & 0.7260 \\
\hline \hline NYSE No Granger Cause BSE_30 & 293 & 9.25549 & 0.0001 \\
BSE_30 No Granger Cause NYSE & & 1.43271 & 0.2404 \\
\hline \hline S\&P_500 does not Granger Cause BSE_30 & 293 & 9.12137 & 0.0001 \\
BSE_30 does not Granger Cause S\&P_500 & & 1.36724 & 0.2565 \\
\hline \hline SSE_composite does not Granger Cause BSE_30 & 293 & 2.98305 & 0.0522 \\
BSE_30 does not Granger Cause SSE_composite & & 0.10271 & 0.9024 \\
\hline \hline NYSE does not Granger Cause NIKKEI_225 & 293 & 11.4664 & $2 . E-05$ \\
NIKKEI_225 does not Granger Cause NYSE & & 1.04198 & 0.3541 \\
\hline \hline S\&P 500 does not Granger Cause NIKKEI_225 & 293 & 15.3605 & $5 . E-07$ \\
NIKKEI_225 does not Granger Cause S\&P_500 & & 0.92904 & 0.3961 \\
\hline \hline SSE_composite does not Granger Cause NIKKEI_225 & 293 & 1.43937 & 0.2388 \\
NIKKEI_225 does not Granger Cause SSE_composite & & 0.59190 & 0.5539 \\
\hline \hline S\&P_500 does not Granger Cause NYSE & 293 & 2.62299 & 0.0543 \\
NYSE does not Granger Cause S\&P 500 & & 2.99048 & 0.0518 \\
\hline \hline SSE_composite does not Granger Cause NYSE & 293 & 2.07262 & 0.1277 \\
NYSE does not Granger Cause SSE_composite & & 0.11339 & 0.8928 \\
\hline \hline SSE_INDEX does not Granger Cause SP_INDEX & 293 & 2.15069 & 0.1183 \\
SP_INDEX does not Granger Cause SSE_INDEX & 0.10105 & 0.9039
\end{tabular}

Table 7 shows the Granger Causality test result for the stock markets during the financial crisis. From the figures we can say that BSE-30 received volatility spillover from all stock markets. Moreover Nikkei-225 received volatility transmission only from USA stock markets. USA stock markets have bidirectional influences on each other but didn't receive any volatility spillover from Asian stock markets. China stock exchange doesn't receive any volatility spillover from stock exchanges.

\section{Conclusion}

From the empirical results we can conclude that global financial meltdown diminished stock returns of all stock markets. The global financial crisis increased volatility of stock returns of USA stock markets in large extent whereas major Asian countries 
stock markets had comparatively less volatility in stock returns than USA ones. EGARCH model result reveals that China's stock exchange less affected by the crisis than the other stock markets whereas financial meltdown influenced USA stock markets in large extent. Granger Causality test shows that after the onset of the financial crisis, the USA stock markets have bidirectional influences on each other, but didn't receive any volatility spillover from major Asian countries stock markets. Indian stock market receives volatility spillover from all the stock markets. Japanese stock market receives volatility spillover only from USA stock markets. Chinese stock exchange doesn't receive any volatility spillover from stock exchanges which examined in this paper.

One of the main findings is that according to the estimated results of E-GARCH model Shanghai Composite Stock Index (SSE) is less effected by the global financial crisis compering with the major Asian countries (namely, Japan and India. In addition to that, Granger Causality test supports that Chinese Stock Exchange is not subject to any volatility spillover from US, Japan and India. One of the reasons is that China is partially liberalized country. Financial system of the country could be immune to adverse effect of financial dissolving. On the other hand, when the global slowdown became apparent, the Chinese government shifted economic policy direction rapidly and vigorously. In November 2008, Chine started to implement a very large stimulus package with amount 4 trillion Yuan ( $\$ 580$ billion). Due to expansionary fiscal policy and monetary policy China could provide positive growth during the global slowdown.

\section{References}

ABIDIN, S. (2012). Is There Asymmetric Volatility in New Zealand During the Global Financial Crisis? Available at http://papers.ssrn.com/sol3/papers.cfm?abstract_id=2187679 http://dx.doi.org/10.2139/ssrn.2187679

ADAMU, A. (2010). Global financial crisis and Nigerian stock market volatility. Proceedings of the National Conference on "Managing the Challenges of Global Financial Crisis in Developing Economies". 2010, Vol. 1, p. 102-113.

ADAS, C. G. and KARTALLI, F. Y. (2014). Sudden Stops, Capital Controls and When to Apply. Journal of Faculty of Economics, Istanbul University. 2014, Vol. 65, No.1, p.1-38.

ENGLE, R. (2001). GARCH 101: The Use of ARCH/GARCH Models in Applied Econometrics. Journal of Economic Perspectives. 2001, Vol. 15, No. 4, p. 157-168. http://dx.doi.org/10.1257/jep.15.4.157

FORBES, K. and RIGOBON, R. (1999). No Contagion, only Interdependence: Measuring Stock Market Co-Movement. NBER Working Paper Series. 1999, No. 7267.

GRANGER, C. W. J. (1969). Investigating Causal Relations by Econometric Models and Cross-spectral Methods. Econometrica. 1969, Vol. 37, No. 3, p. 424-438. http://dx.doi.org/10.2307/1912791 
KARANASOS, M. and KIM, J. (2003). Moments of the ARMA-EGARCH model. Econometrics Journal. 2003, Vol. 6, p. 146-166. http://dx.doi.org/10.1111/1368-423x.00104

KE, J., WANG, L. and MURRAY, L. (2010). An empirical analysis of the volatility spillover effect between primary stock markets abroad and China. Journal of Chinese Economic and Business Studies. 2010, Vol. 8, No. 3, p. 315-333. http://dx.doi.org/10.1080/14765284.2010.493645

LIM, K.; BROOKS, R. and KIM, J. (2008). Financial crisis and stock market efficiency: Empirical evidence from Asian countries. International Review of Financial Analysis. 2008, Vol. 17, No. 3 , p. 571-591. http://dx.doi.org/10.1016/j.irfa.2007.03.001

OLOWE, R. A. (2009). Stock return, volatility and the global financial crisis in an emerging market: the Nigerian case. International Review of Business Research Papers. 2009, Vol. 5, No. 4, p. 426447.

RAFAGET, A. and AFZAL, M. (2012). Impact of global financial crisis on stock markets: Evidence from Pakistan and India. E3 Journal of Business Management and Economics. 2012, Vol. 3, No. 7, p. 275-282.

ROYFAIZAL, R. C.; LEE, C. and AZALI, M. (2009). ASEAN-5 + 3 and US Stock Markets Interdependence Before, During and After Asian Financial Crisis. International Journal of Economics and Finance. 2009, Vol. 1, No. 2, p. 45-54. http://dx.doi.org/10.5539/ijef.v1n2p45

SAKTHIVEL, P.; BODKHE, N. and KAMAIAH, B. (2012). Correlation and Volatility Transmission across International Stock Markets: A Bivariate GARCH Analysis. International Journal of Economics and Finance. 2012, Vol. 4, No. 3, p. 253-264. http://dx.doi.org/10.5539/ijef.v4n3p253

SAKTHIVEL, P. and KAMAIAH, B. (2012). Interlinkages among Asian, European and the U.S stock markets: A Multivariate Cointegration analysis. Journal of Economics and Behavioral Studies. 2012, Vol. 4, No. 3, p. 129-141.

SETH, A. (2007). Granger causality. Scholarpedia. 2007, 2(7):1667. http://dx.doi.org/10.4249/scholarpedia. 1667

SINGH, G. S. P. (2010). Chinese and Indian Stock Market Linkages with Developed Stock Markets. Asian Journal of Finance \& Accounting. 2010, Vol. 2, No. 2, p. 21-39.

STERN, D. I. (2011). From Correlation to Granger Causality. Crawford School Research Paper No 13, Paper presented at the AIJOS Capstone Conference, University of Michigan, Ann Arbor MI, 2930 September 2011. Available at: $\underline{\text { http://ssrn.com/abstract }=1959624}$ http://dx.doi.org/10.2139/ssrn.1959624

SULEMAN, M. T. (2012). Stock Market Reaction to Good and Bad Political News. Asian Journal of Finance \& Accounting. 2012, Vol. 4, No. 1, p. 299-312. http://dx.doi.org/10.5296/ajfa.v4i1.1705

VERMA, S. and MAHAJAN, N. (2012). Stock return, volatility and the global financial meltdown: the behavior of Indian stock market. International Journal of Arts and Commerce. 2012, Vol. 1, No. 7, p. 166-178. 